\title{
Effect of Inundation on Shear Strength Characteristics of Mudstone Backfill.
}

\begin{abstract}
A group of lithologies which includes claystone, siltstone, mudstone and shale also known as mudrocks are indurated sediments widely encountered throughout the world. Shear strength and deformation characteristics of mudstone were investigated using a fully automated hydraulic stress path testing system under three rock states: dry, short-term inundated, and long-term. It is observed that the maximum deviator stress, q appeared to decrease meaning the strength deteriorated as the rock states changed from dry to wetted and to degraded conditions. Furthermore, critical state interpretations of the mudstone under all three rock states have shown unique high curved Mohr-Coulomb failure envelopes which are normally exhibited only by crushable soil. Nevertheless, $M$ which is the slope of stress path and angle shearing resistance values, $\phi^{\prime}$ obtained from dry specimens were always higher than the partially saturated specimens. However, as dry mudstone sheared under higher mean effective stress $(700 \mathrm{kPa})$, the $\mathrm{M}$ value exhibited is similar to $\mathrm{M}$ value of wetted mudstone which is 1.20 and remained the same as mudstone degraded. It is believed that the strength of mudstone decreasing as it begins to crush and gradually became constant.
\end{abstract}

Keyword: Mudrock; Shear strength; Soft rock; Partial saturation; Inundation; Mudstone 